\title{
Investigation of the Effects of Agitation on the Hardening Characteristics of Medium Carbon Steel Quenched in Non-Edible Seed Oils Grown in Nigeria
}

\author{
Ishaq T. Muhammad, Abdulrauf A. Ibrahim, and Hayatudeen Ibrahim \\ Department of Mechanical Engineering \\ College of Engineering, Kaduna polytechnic \\ Kaduna. Nigeria
}

\begin{abstract}
This research evaluates the forced circulation of various quenchants (jatropha seed oil, neem seed oil, cottonseed oil and castor seed oil) in a fabricated quenching machine to reduce the cooling time and analyse the hardening characteristics of samples of low and medium carbon steel in these media. The samples were quenched in water and SAE engine oil for control experimentation. The microstructures and mechanical properties of the quenched samples were used to evaluate the quench severity of the various quenchants as well as the hardening characteristics of the samples.

The focus of this investigation is to find the suitability or otherwise of non-edible oils abundantly available in Nigeria as effective alternatives to the conventional media, water and SAE oil. While water usually causes distortion corrosion and cracking of component due to its high quenching severity, SAE oil, on the other hand, has low quenching severity for many applications, high cost, non-biodegradable and excessive fume generation during the quenching operations. These will successful gave rise to investments and employment in the cultivation and processing of these non-edible seed oils thereby lending support towards achieving sustainable development through environmental protection.
\end{abstract}

Keywords: Biodegradable, Edible seeds, Jatropha, Quenchants, SAE oil.

\section{INTRODUCTION}

The commonly used quenching media are water, SAE oil, brine, and synthetic solutions. Water though abundant and low cost has the drawback of inducing crack or dimensional changes on the quenched component due to its high cooling rate and oil has the problem of not inducing enough hardness. Polymer quenchants though can provide severity between those of water and oil but has the problem of varying concentration during the quenching process and it is also more expensive.

Brine produces more quenching severity than water; but it also has a problem of corrosive attack on the components and the equipment used for the quenching operation. Therefore there is a need for the development of a quenching medium with good economics like water, environmentally friendly and having less severity of quench and yet producing appreciable hardening characteristics [4] Hence this work is aimed at investigating the suitability of using various non-edible seed oils as alternative quenching media for hardening process in low and medium steels, with and without agitation effects.

No doubt, the ferrous metal group (steels \& cast irons) constitute the most widely used in engineering this is because this alloy group has many applications including, automobile, construction, electrical \& electronics, domestic appliances, marine, aeronautics, nuclear etc. fields [5]. Again this feat is possible due to the fact that different properties can be developed in these metals to meet the demands of numerous applications by both alloying process and thermal process called heat treatment. Heat treatment involves heating the ferrous metal into the austenite temperature range and followed by a controlled cooling such as in the furnace (annealing), air (normalizing) or a liquid medium (quenching/ hardening) [ 2] 
Hardening essentially involves heating the metal alloy to a sufficiently high temperature, holding at that temperature followed by rapid cooling in a media usually water, oil or salt bath [1] This consequently causes an increase in hardness of the metal/alloy, which due to phase transformation which accompany rapid cooling that occur at a considerably low temperature leading to the formation of non-equilibrium products [3] The transforming phase is austenite and the product of low temperature transformation of austenite is martensite which is a hard micro-constituent in steel [6],. The presence of this micro constituent in rapidly cooled steels thus accounts for the increase in hardness of steel [7]

Due to internal stress quenched steel and ductile cast iron is extremely hard but brittle, Therefore the quenching process is followed by another heat treatment process called tempering when the component cannot be used is as quenched condition.

Plain carbon steels are widely used for many industrial applications and manufacturing on account of their low cost and easy fabrication [8]. They are classified on the basis of their carbon content as their major alloying element is carbon. According to [7] steels with carbon content varying from $0.3 \%$ to $0.6 \%$ are classified as medium carbon, while those with carbon content less than $0.3 \%$ are termed low carbon. The carbon content of high carbon steels usually ranges within $0.6-1.5 \%$. Hardness and other mechanical properties of plain carbon steels increase with the rise in concentration of carbon dissolved in austenite prior to quenching during hardening heat treatment [Shuhui Ma 2006], which may be due to transformation of austenite into martensite [7] Therefore, the mechanical strength of medium carbon steels can be improved by quenching in appropriate medium. However, the major influencing factors in the choice of the quenching medium are composition of the steel, the sizes and shapes of the parts [7] Applications of steels for engineering components require a complete understanding of material properties and design requirements. Through the last few decades a category of steels known as high strength steels have undergone constant research [Srikanth.V2003]. As a result, quenched and tempered micro alloyed steels are most likely candidate materials for the next generation of high - strength steel sheets. For a given alloy content, quenched and tempered micro alloyed steel exhibit good combination of strength and toughness [7]

Traditionally, quenched and tempered steel sheets are employed in automotive industry in the areas of structural members, power transmission and impact resistance systems. Certain engineering components require high hardness values so that they may be used successfully for heavy duty processes. Hardening as a form of heat treatment has been used to achieve these requirements in metal or alloy components.

\subsection{METHODOLOGY}

A quenching tank was Design and constructed with a variable electric motor incorporated. The design of the quenching machine is as follows:

Volume of tank was determined using equation

$v=\frac{\pi}{4} D^{2} H$ where, $\mathrm{V}=$ Volume of tank, $\mathrm{D}=$ Diameter of tank, $\mathrm{H}=$ Height of tank.

Control switch

All electrical connections will be at normal for liquid tight box. An On/Off will be included for the electric heater and a Start/Stop button for the agitation circuits inside the box. The control switch voltage is $240 \mathrm{~V}$.

Shaft coupling and Keyway

A sleeve coupling will be designed to transmit full torque by means of a key and a sleeve from electric motor to the agitator and to reduce transmission shock load during operation.

Electric motor selection The electric motor used is $0.5 \mathrm{Hp}$ with a maximum speed of $1400 \mathrm{rpm}$.

The chemical composition of the medium carbon steel samples to be used for this investigation was obtained.

\subsection{Material}

The materials used was medium carbon steel obtained from Katsina steel company limited,KatsinaState, Nigeria. The chemical composition of the steel is obtained and the oils under investigation are non-edible seeds of castor, Neem and Jatropha which are readily available in Nigeria, while the SAE40 engine oil and tap water served as control used forcomparison in this study. The non-edible oils [jatropha, Neem and castor] were obtained from NARICT Research Centre, Zaria].

\subsection{Equipment}

The equipment used in this work includes: Agitation machine Lathe machine, heat treatment furnace, Avery Denison Izod impact machine, Monso Tensometer, Avery hardness machine.

\subsection{METHOD}


Test Samples was machined from the medium carbon steel. One set of the machined test samples from medium carbon steel (for hardness, tensile and impact) will be kept aside to be tested in the as-received condition,. The remaining samples in each case will be taken into the furnace and austenitized at $880 \mathrm{oC}$ for medium carbon, and soaked using a furnace for $1 \mathrm{hr}$ before been removed and cooled in air.

The samples will be taken back into the furnace and heated to $880{ }^{0} \mathrm{C}$ again; soaked for $1 \mathrm{hr}$ after which a set of test samples for (hardness, tensile, impact) each will be removed and quenched in water, SAE engine oil castor, Jatropha respectively. The quenched samples will then be removed, cleaned and subjected to hardness, tensile and impact tests respectively.

\subsection{Production of test pieces}

The test piece sample was selected from building rod of $10 \mathrm{~mm}$ diameter. A sample was taken for composition test to know the carbon percentage in the sample. The composition test was done using a spectrometer. The test result shows that it is a medium carbon steel with carbon content of $0.55 \%$. The test pieces were produced from the same material [building rod] and machined for three major tests; tensile, impact and hardness test. Seventeen test pieces were produced for each test, that is fifty one specimens in total.

\subsection{Heating process}

First of all, three of the specimens were set aside as received, the remaining test specimens were normalized; that is to say they were heated in the furnace at $880{ }^{\circ} \mathrm{C}$, then the temperature $\left[880{ }^{\circ} \mathrm{C}\right]$ was maintained for 30minutes after which it was allowed to cool down in air [quenching in air].a set of the specimen was set aside again as normalized specimen. After normalizing, the specimens were heated to $880{ }^{\circ} \mathrm{C}$ and then quenched in the four quenching mediums [Jatropha, SAE, water and castor oil]. The specimens were grouped in three per batch with respect to the three tests[tensile, impact and hardness] .The quenching process was carried out in four different conditions for each quenchant ;for no agitation, low speed agitation, medium speed agitation and high speed agitation. An agitation speed $3000 \mathrm{rpm}$ was the optimum speed to produce maximum increase in hardness.

\begin{tabular}{llllll}
\hline \multicolumn{1}{l}{ Table 1. Agitation Procedures } & & & \\
\hline Quenchants & Agitation Conditions & & & \\
& No & agitation & Low speed agitation \\
Samples & Samples & $\begin{array}{l}\text { Medium } \\
\text { agitation samples }\end{array}$ & $\begin{array}{l}\text { High speed agitation } \\
\text { Samples }\end{array}$ \\
Jatropha & 3 & 3 & 3 & 3 \\
Neem & 3 & 3 & 3 & 3 \\
Castor & 3 & 3 & 3 & 3 \\
Water & 3 & 3 & 3 & 3 \\
SAE & 3 & 3 & 3 & 3 \\
\hline
\end{tabular}

For each of the three sets of specimen tensile, impact and hardness test specimen with respect to agitating conditions were performed.

TABLE 2: Impact test specimen with respect to agitating conditions

\begin{tabular}{lll}
\hline $\mathbf{S} / \mathbf{N}$ & Specimen & Impact Energy (Joules) \\
\hline $\mathbf{1}$ & SAE[No agitation] & 133.65 \\
$\mathbf{2}$ & SAE[low agitation] & 11.45 \\
$\mathbf{3}$ & SAE[Medium agitation] & 168.75 \\
$\mathbf{4}$ & SAE[High agitation] & 94.50 \\
$\mathbf{5}$ & Water[No agitation] & 171.45 \\
$\mathbf{6}$ & Water[low agitation] & 12.15 \\
$\mathbf{7}$ & Water[Medium agitation] & 24.30 \\
$\mathbf{8}$ & Water[High agitation] & 13.17 \\
$\mathbf{9}$ & Castor[No agitation] & 162.00 \\
$\mathbf{1 0}$ & Castor [low agitation] & 91.80 \\
$\mathbf{1 2}$ & Castor [Medium agitation] & 72.90 \\
$\mathbf{1 3}$ & Castor [High agitation] & 86.40 \\
$\mathbf{1 4}$ & Jatropha [No agitation] & 117.45 \\
$\mathbf{1 5}$ & Jatropha [low agitation] & 226.80 \\
\hline
\end{tabular}


International Journal of Advances in Scientific Research and Engineering (ijasre),Vol 5 (3), March-2019

\begin{tabular}{lll}
\hline $\mathbf{1 6}$ & Jatropha [High agitation] & 82.35 \\
$\mathbf{1 7}$ & Neem [No agitation] & 98.22 \\
$\mathbf{1 8}$ & Neem [low agitation] & 102.11 \\
$\mathbf{1 9}$ & Neem [Medium agitation] & 145.43 \\
$\mathbf{2 0}$ & Neem [High agitation] & 179.33 \\
$\mathbf{2 2}$ & Normalized & 91.80 \\
\hline
\end{tabular}

This experiment was repeated for tensile and hardness test piece as follows:

Hardness values were determined from the as-quenched specimens. The hardness impressions were taken transversely in two perpendicular directions along the cross-section of the quenched steel specimens using Rockwell hardness testing machine (Leco LM 700 AT) under applied load of 477.5 MN and dwell time of 9 sec. on a "C" scale (HRC). Hardness values were recorded for the three samples [No agitation, low agitation and high agitation]

Tensile tests were conducted on an Instron Universal Testing machine Model 3369 by using standard tensile test specimens of 10 $\mathrm{mm}$ in diameter and gauge length of $25 \mathrm{~mm}$. The tensile strength, percentage reduction inarea and percentage elongation were determined from the Load-extension curves. The impact energy test was carried out to measure the toughness of the as-quenched steel specimens on Izod impact testing machine ModelIT-30 according to ASTM D256 in various selected quenching media.

\subsection{RESULTS AND DISCUSSION}

Table 3 gives the average chemical composition of the steel used. The effect of selected quenching media on the mechanical properties of the quenched medium carbon steel is entered in Table 4. Figures 1-4 are the bar charts of hardness values, tensile strength, percentage elongation, and impact energy of the quenched medium carbon steel.

.The quenching characteristics of medium carbon steel in the selected vegetable oils were studied in this research work to evaluate the possibility of using vegetable oils as alternative quenchant to SAE40 engine oil for industrial heat treatment of Medium Carbon steels. The hardness, tensile strength, percent elongation, percent reduction in area and impact energy were used as major criteria in assessing each vegetable oil under investigation. The study has shown that an increase in the speed of an agitation machine increases the mechanical properties of the specimen, hence the values for high speed agitation were considered in determining the most suitable quenchants.

\begin{tabular}{llllllll}
\hline \multicolumn{6}{c}{ Table 3. Chemical composition by weight of medium carbon steel(chem. Lab Kaduna Poly) } \\
\hline Elements & $\mathrm{Si}$ & $\mathrm{Mn}$ & $\mathrm{C}$ & $\mathrm{P}$ & $\mathrm{S}$ & $\mathrm{Fe}$ & $\mathrm{Cr}$ \\
$\begin{array}{l}\text { Percentage } \\
\text { composition }\end{array}$ & 0.16 & 0.7 & 0.3 & 0.03 & 0.041 & 98.2 & 0.41 \\
\hline
\end{tabular}

TABLE 4

\begin{tabular}{|c|c|c|c|c|}
\hline Quenched sample & $\begin{array}{l}\text { Average tensile } \\
\text { strength }(\mathrm{Nmm} 2)\end{array}$ & Hardness(HRC) & $\begin{array}{ll}\text { Izod } & \text { Impact } \\
\text { value }(\mathrm{J} / \mathrm{m}) & \end{array}$ & $\begin{array}{l}\text { Percentage } \\
\text { elongation(\%) }\end{array}$ \\
\hline $\begin{array}{l}\text { Neem seed oil } \\
\text { quenched }\end{array}$ & 520 & 13.0 & 16 & 0.5 \\
\hline $\begin{array}{l}\text { Jatrophaseed oil } \\
\text { quenched }\end{array}$ & 420 & 29.2 & 12 & 0.4 \\
\hline $\begin{array}{l}\text { Castor oil seed } \\
\text { quenched }\end{array}$ & 410 & 22.2 & 13 & 0.3 \\
\hline $\begin{array}{l}\text { SAE Engine oil } \\
\text { quenched }\end{array}$ & 480 & 21,22 & 0.4 & 0.2 \\
\hline Water quenched & 230 & 48.23 & 1 & 0.2 \\
\hline As received & 568 & 9.9 & 29 & 0.7 \\
\hline
\end{tabular}


International Journal of Advances in Scientific Research and Engineering (ijasre),Vol 5 (3), March-2019

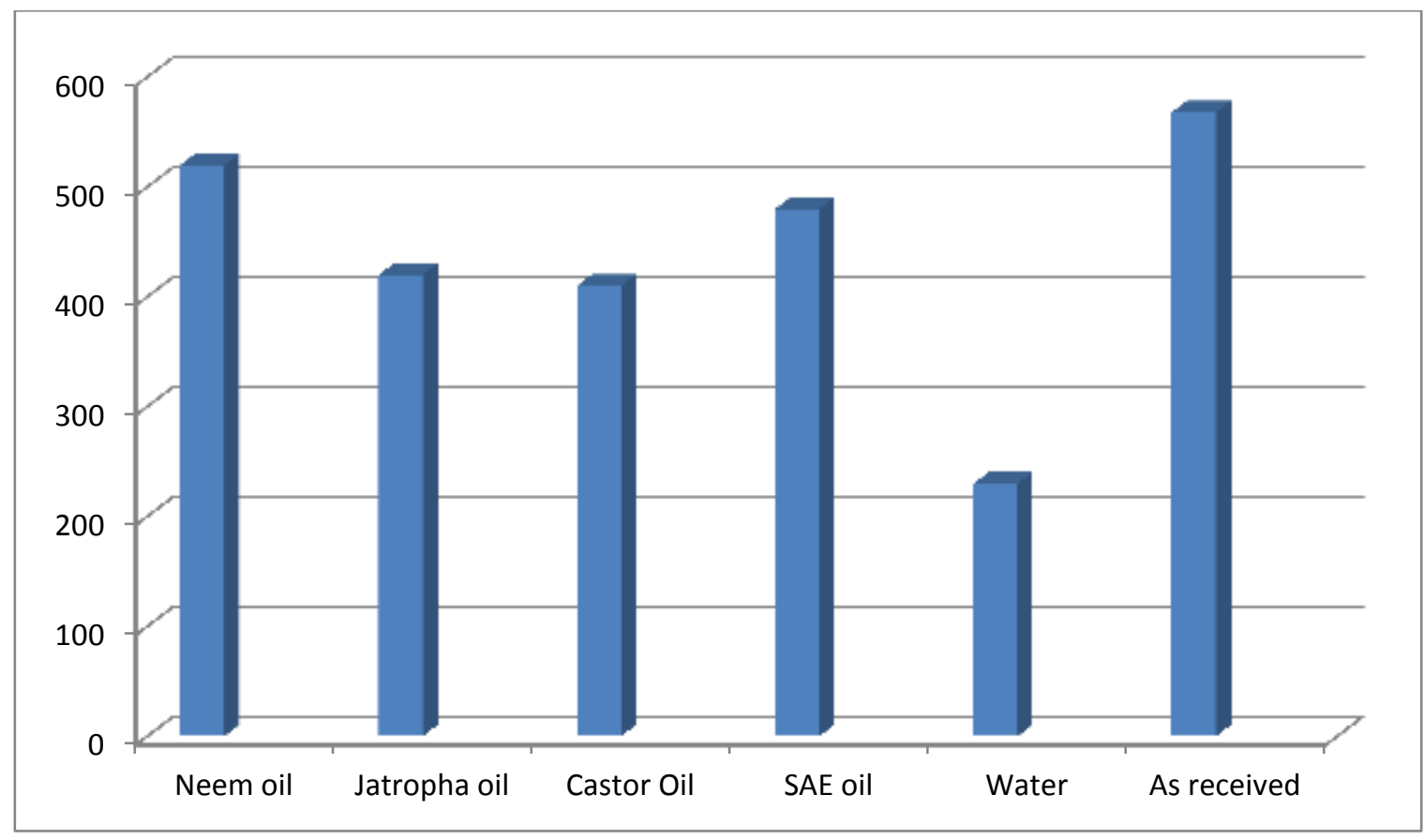

Fig.1 Tensile strength of steel in various quenchants at high agitation speed

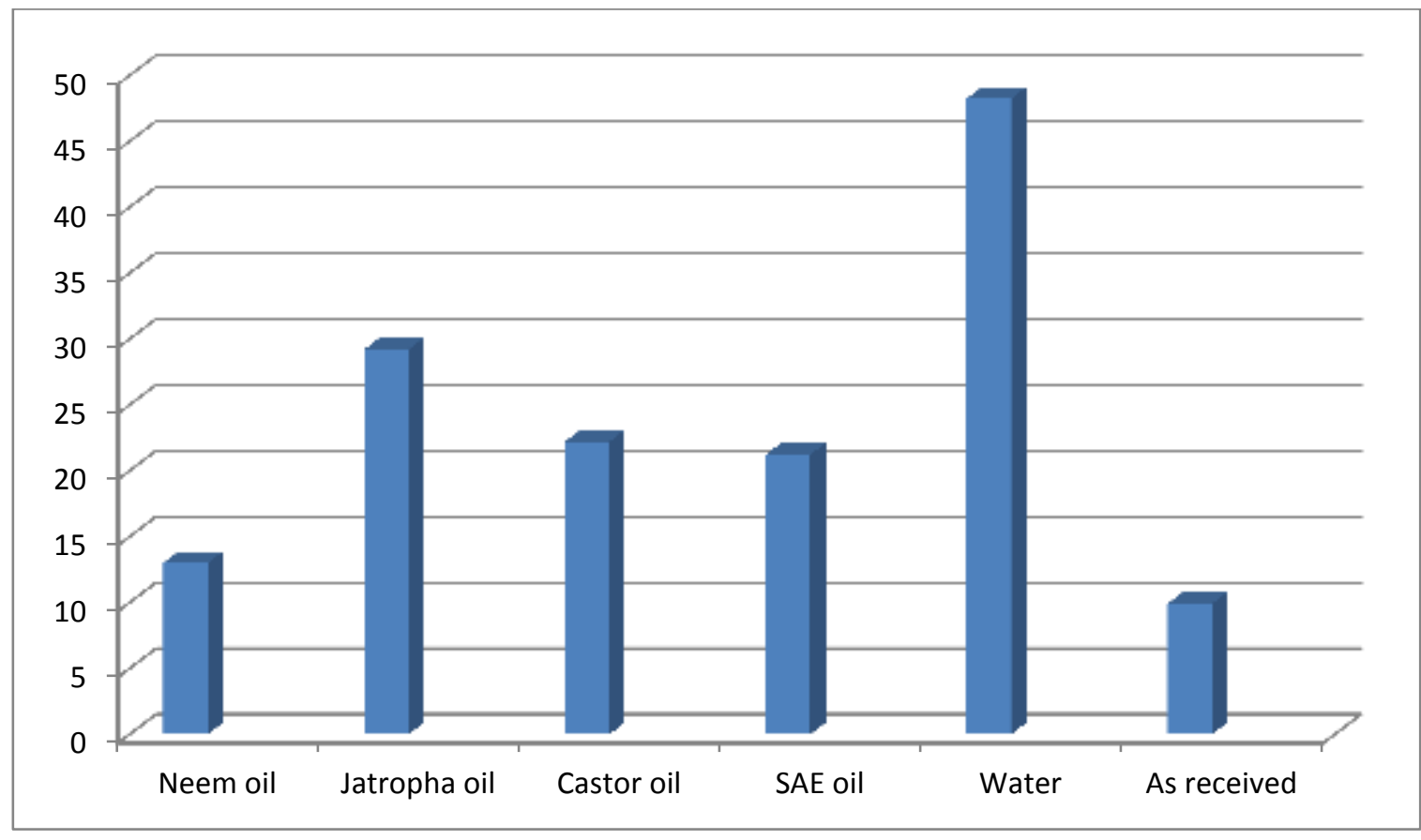

Fig 2. Hardness of sample quenched at high speed in various quenchants 


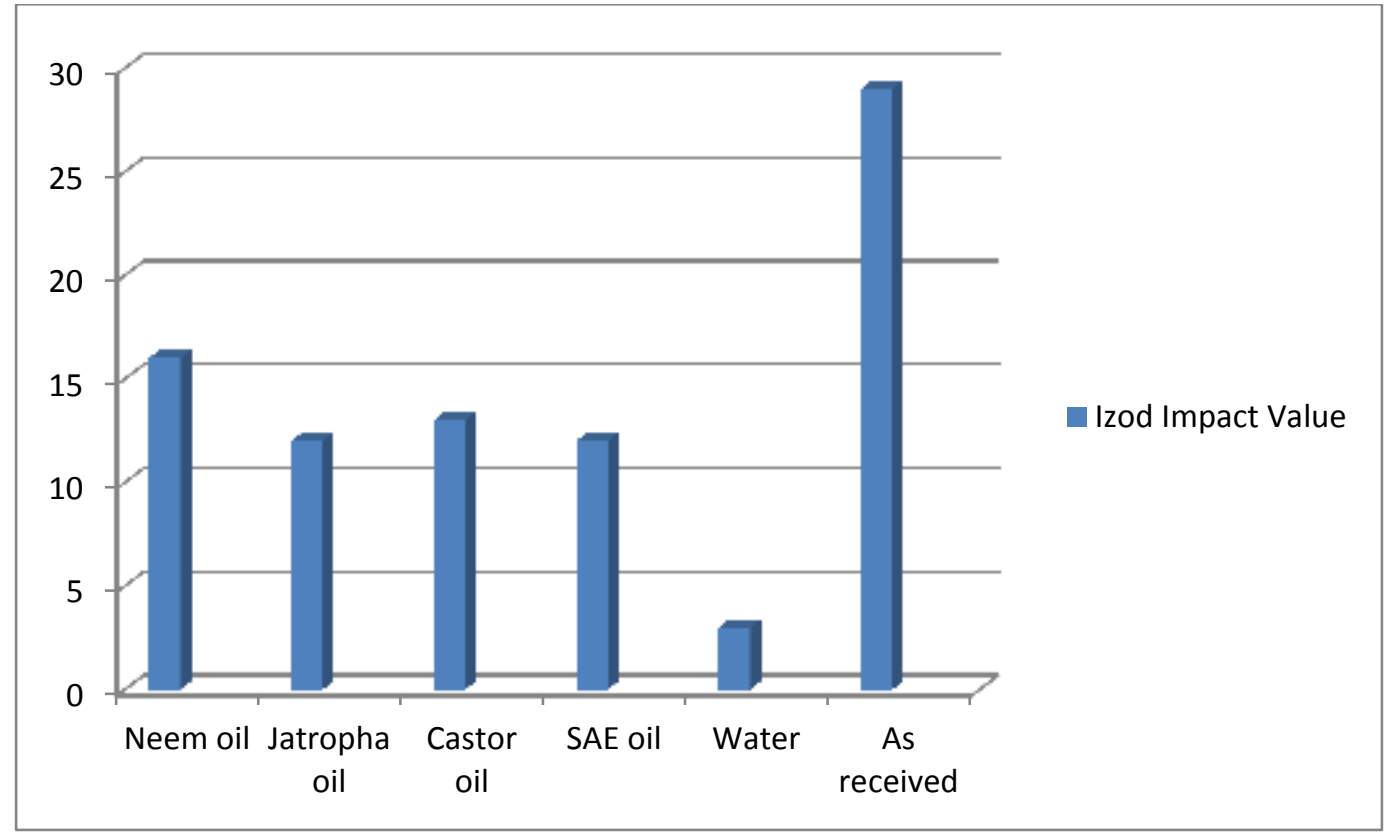

Fig 3.Izod impact values of samples quenched in various samples at high speed

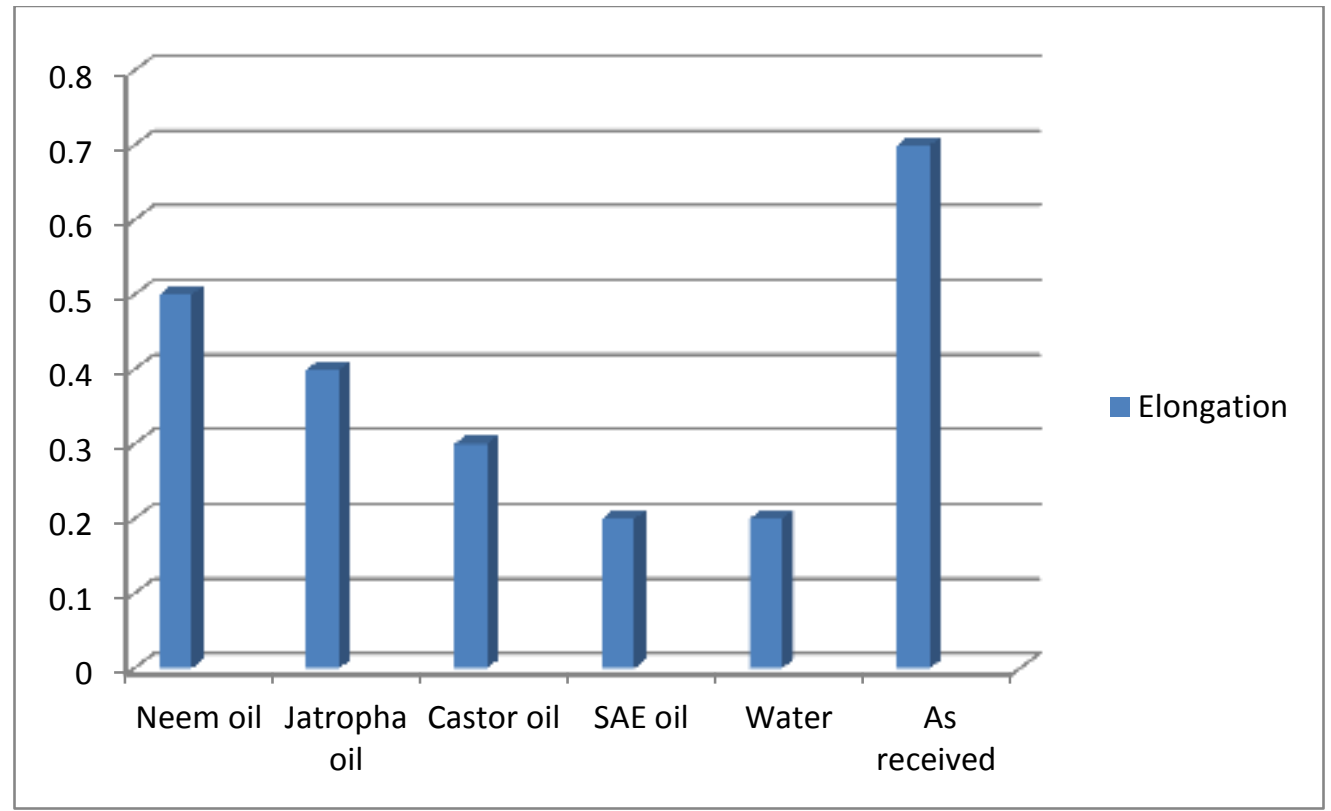

Fig 4. Percentage elongation of samples quenched at high agitation speed in various quenchants

Non edible seeds vegetable oil quenched specimens exhibited higher Izod impact values compare to the water-quenched specimen and there was no cracks observed in the specimens indicating suitability of the media for quenching of this particular specimen. Neem oil quenched sample exhibited superior mechanical properties in relation to hardness values compared to other vegetable oils used.

\section{CONCLUSIONS}

An agitation speed $3000 \mathrm{rpm}$ was the optimum speed to produce maximum increase in hardness; this shows that an increase in speed shows an improvement of the mechanical properties of metal during heat treatment process. Therefore an agitation tank with variable speed has proved to be effective for quench hardening heat treatment.

At the completion of the research work, the severity of various quenchants was determined; the effect of agitation on the hardening characteristics of test samples through variable agitation rate was also obtained and compared with test samples using 
SAE engine oil and water as quenchants. The derivatives from this comparismgives the non-edible seed oil a better alternative in terms of quench severity, commercial availability, and environmentally friendliness. Two of the vegetable oils (Jatropha and Castor seed) exhibited substantially fast cooling during thequenching period as reflected by their hardness values obtained which suggest that they would be suitable as alternative to petroleum based SAE40 engine oil for quenching low hardenability steels such as medium carbon steels without cracking or distortion. The most suitable among them being Jatropha oil based on mechanical properties of its quenched steel sample as compared to others.Based on the heat flow parameters, Jatropha oil can be used as fast quench medium while Castor seed oiland neem seed oil may be used as slow quench oil. Among the oils tested, Neem oil exhibited the least quenching ability.

Average hardness value ranked in descending order as: Water $>$ Jatropha seed oil $>$ SAE40 $>$ Castor oil $>$ Neem seed oil.

\section{ACKNOWLEDGEMENT}

We acknowledge Tertiary Education Trust Fund (TETFUND) as our sponsors

\section{REFERENCES}

1. A. Yekinni 2014 Fabrication of End Quenched Machine Hardenability Evaluation Journal of Minerals and Materials Characterization and Engineering, 2014, 2, 107-113 Published Online March 2014 in SciRes. http://www.scirp.org/journal/jmmce

2. Agboola, J.B. (2014) Performance Assessment of Selected Nigerian Vegetable Oils as Quenching Media during Heat Treatment of Medium Carbon Steel. Ph.D. Thesis, Department of Mechanical Engineering, Federal University of Technology, Minna.

3. Bogh, N. (1994). Quench Tank Agitation Design Using Flow Modeling. Retrieved from www.boghindustries.com/articles/Quench\%20Tank\%20 Callister, Jr. W.D. (1997): "Materials Science and Engineering" 4th edition, John Wiley and Sons Inc. pg 81-215

4. Hassan, S.B, Agboola, J.B., Aigbodion, V.S. and Williams, E.J. (2010) Hardening Characteristics of Plain Carbon Steel and Ductile Cast Iron Using Neem Oil as Quenchant. Journal of Minerals and Materials Characterization and Engineering, 5, 31-36.

5. Kobasco, N.I., Carvalhode Souza, E., Canale, L.C.F. and Totten, G.E. (2010) Vegetable Oil Quenchants: Calculation and Comparison of the Cooling Properties of a Series of Vegetable Oils. Journal of Mechanical Engineering-Slovenia, 56, 131-142.

6. Marufisiaka (2015)Development and performance evaluation of an agitated quenching tank/bath unpublished B. Eng. Finale year project; Department of Mechanical Engineering, A.B.U., Zaria

7. Totten, G.E., Bates, C.E. and Clinton, N.A. (1993) Handbook of Quenchants and Quenching Technology. ASM International, 62, 140-144.

8. Srikanth.V(2003): Establishment of KatsinaNeem Factory, National Research Institute for chemical Technology, Zaria Nigeria. 1-4. 